\title{
Preeclampsia complicated by antenatal and postnatal ascitis
}

\author{
Peter Waibode Alabrah, John Agbo and Eni-yimini Solomon Agoro.
}

\begin{abstract}
Hypertensive disorders of pregnancy are an important cause of severe acute feto-maternal morbidity, lasting disability and mortality. In Africa, about one tenth of all maternal deaths are associated with hypertensive disorders of pregnancy. The majority of deaths attributable to preeclampsia can be circumvented by instituting appropriate and effective care to women presenting with complications one of which is ascitis. Ascitis can lead to dehydration, respiratory failure, heart failure and thromboembolism
\end{abstract}

Index Terms - Preeclampsia, ascites, hypoalbuminaemia, heart failure

\section{INTRODUCTION}

Preeclampsia poses management challenges for the obstetrician and it is a significant contributor to perinatal and maternal morbidity and mortality. The etiology of preeclampsia has lingered unresolved. Ascitis complicating preeclampsia is a rare complication and a manifestation of the multisystem organ exaggeration of preeclampsia. The occurrence of massive ascites causes respiratory distress and predisposes the patient to heart failure. Astute antenatal assessment, knowledge of its occurrence and course, is essential in management of this condition in the post vaginal delivery/Caesarean section patient so as to prevent unintended (re)laparotomy with its associated anaesthetic and surgical complications.

\section{CASE Report}

A 37 year old para $1^{+2}$ lady, booked index pregnancy at 28 weeks gestation. Booking blood pressure was $110 / 60 \mathrm{mmHg}$ and her last confinement was 8 years prior to presentation. The antenatal period was uneventful until 37 weeks when the blood pressure was noted to be $167 / 98 \mathrm{mmHg}$ at routine antenatal visit. No family history of hypertension nor features of imminent eclampsia. Examination revealed, bilateral pitting edema up to the knee, clear lung fields, symphysiofundal height was $34 \mathrm{~cm}$, the fetal heart rate was heard and regular. The Bishop score was 3, clean catch urine dipstick examination revealed $2+$ proteinuria. Ultrasonogram revealed a foetus that was small for gestational age (EFW was $2.2 \mathrm{~kg}$ ), liquor volume was adequate and placenta was anteriorly sited. A moderate amount of ascitic fluid was seen intra-peritoneal. The patient was admitted and commenced on seizure prophylaxis with Mgso4 using the Zuspan regimen. She was commenced on aldomet and nifedipine and she made adequate amount of urine over the next two hours. The laboratory results are shown in table 1 She had Caesarean section for severe preeclampsia with unfavourable cervix. Outcome was a live female infant that weighed $2.3 \mathrm{~kg}$ with Apgar scores, 8 and 9 in 5 and 10 minutes respectively.
Approximately $0.6 \mathrm{~L}$ of straw coloured fluid was drained from the peritoneal cavity. Estimated blood loss at surgery was $500 \mathrm{ml}$. Exploration revealed no other intra-abdominal abnormalities. Magnesium sulphate was continued for 24 hours post-surgery and she had prophylactic antibiotics.

Eight (8) hours post section, the urine output was noticed to have reduced, averaging $21 \mathrm{mls} / \mathrm{hr}$ with accompanying abdominal distension. Abdominal girth was $103 \mathrm{~cm}$ and abdominal paracentesis revealed slightly bloody peritoneal collection. The pulse rate was 94 beats/minute and the blood pressure ranged from 146/85 to 168/102mmHg. Fluid intake was maintained at 3litres/24hours, hourly monitoring of urine output and antihypertensive (aldomet and nifedipine ) was commenced. The abdominal girth increased to $106 \mathrm{~cm}$ on the $1^{\text {st }}$ day post section and her hemogram was $8.2 \mathrm{~g} / / \mathrm{dl}$ on the $2^{\text {nd }}$ day post section. Urine output averaged $52 \mathrm{ml} /$ hour.

Table 1: LABORATORY RESULTS

\begin{tabular}{|c|c|c|c|c|c|}
\hline & $\begin{array}{c}\text { Day of } \\
\text { C/S }\end{array}$ & $\begin{array}{c}1^{\text {st }} \\
\text { DPO }\end{array}$ & $\begin{array}{r}2^{\text {nd }} \\
\text { DPO }\end{array}$ & $\begin{array}{c}3^{\text {rd }} \\
\text { DPO }\end{array}$ & $\begin{array}{c}4^{\text {th }} \\
\text { DPO }\end{array}$ \\
\hline Hemoglobin (g/dl) & 9 & - & 8.3 & - & 10.3 \\
\hline Haematocrit (\%) & 27 & - & 25 & - & 31 \\
\hline $\mathrm{WBC}\left(\mathrm{mm}^{3}\right) \times 100$ & 153 & - & 168 & - & 169 \\
\hline $\begin{array}{l}\text { Platelet count } \times 10^{3} \\
(/ \mathrm{L})\end{array}$ & 198 & - & 211 & - & 218 \\
\hline $\mathrm{Na}(\mathrm{mmol} / \mathrm{L})$ & 128 & 130 & 129 & 131 & 135 \\
\hline $\mathrm{K}(\mathrm{mmol} / \mathrm{L})$ & 3.8 & 3.0 & 3.4 & 3.2 & 3.3 \\
\hline $\mathrm{Cl}(\mathrm{mmol} / \mathrm{L})$ & 97 & 99 & 95 & 100 & $\begin{array}{c}10 \\
1\end{array}$ \\
\hline Creatinine(mg/dl) & 0.9 & - & 0.8 & 0.7 & 0.6 \\
\hline Urea $(\mathrm{mg} / \mathrm{dl})$ & 48 & - & 39 & 38 & 32 \\
\hline $\operatorname{ALT}(\mathrm{U} / 1)$ & 28 & - & 22 & - & - \\
\hline AST(U/1) & 18 & - & 15 & - & - \\
\hline Alk phosph. (U/1) & 110 & - & 121 & - & - \\
\hline Tot. bilirubin(mg/dl) & 2.7 & - & 2.2 & - & - \\
\hline Dir. bilirubin(mg/dl) & 1.3 & - & 1.1 & - & - \\
\hline Total protein(g/l) & 4.6 & - & 4.7 & - & 4.9 \\
\hline Albumin (g/L) & 2.5 & - & 2.7 & - & 2.8 \\
\hline
\end{tabular}

DPO Post-operative day, ALT: alanine transaminase, AST: Aspartase

transaminase, Alk phosph: alkaline phosphatase, Dir: direct

She developed heart failure on the $3^{\text {rd }}$ day post operation and she was co-managed with the physicians with blood transfusion (3 units of fresh whole blood), oxygen administration, spironolactone and frusemide. The abdominal girth which peaked on the $3^{\text {rd }}$ day post-surgery at $109 \mathrm{~cm}$ progressively regressed from the fifth day post- 
surgery. The haemogram was $10.9 \mathrm{~g} / \mathrm{dl}$ on the $6^{\text {th }}$ day post section. She was discharged on the $8^{\text {th }}$ day post-surgery, the abdominal girth was $94 \mathrm{~cm}$, and the antihypertensives were subsequently tailed off and stopped 24 days postpartum. At the postnatal visit the blood pressure was normal at 100/60mmHg.

\section{DISCUSSION}

Ascites has been reported in pregnancies ${ }^{1}$ and at cesarean section delivery in pregnancies complicated by preeclampsia ${ }^{2-4}$. The pathophysiology of peritoneal fluid collection in preeclampsia has remained uncertain ${ }^{2}$. However, the most contemporary concept implicates the release of vasoconstrictive mediators, and widespread endothelial cell injury. The endothelial damage at the capillary level, affects the capillary microcirculation resulting in unbridled permeability at the capillary end and microangiopathy.

Several researchers have reported abnormalities in serum proteins in preeclampsia complicated by ascitis ${ }^{3-6}$. Albumin does not diffuse liberally through intact vascular endothelium. Hence, it is the chief protein that ensures the critical colloid osmotic or oncotic pressure that regulates the route, water and diffusable solutes passes through the capillaries.

Impairment of endothelial barrier function manifests as generalized capillary leak ${ }^{4}$ and albumin which comprises only about $50-60 \%$ of the total protein content of plasma, but is responsible for about $80 \%$ of intravascular colloid oncotic pressure, diffuses freely through the dysfunctional vascular endothelium ${ }^{5}$ and results in reduction of serum albumin. The import of hypoalbuminemia is the transferal of fluid from the intravascular compartment to the interstitial space, resulting in intravascular volume depletion and a consequent low colloid osmotic pressure. This invariably results in effusion causing ascites ${ }^{8}$. This may be the reason for the accumulation of fluid in the peritoneal cavity and the subsequent abdominal distension. After abdominal surgery there is always blood in the peritoneal cavity, this mixed with the peritoneal collection may give the erroneous belief of continuous intraabdominal bleeding.

Albumin in this case ranged from $54.3 \%$ to $57.7 \%$ of the total protein. However, serum albumin (as shown in the table above) is below the normal range of 3.5 to $5 \mathrm{~g} / \mathrm{dl}$ but with the delivery of the fetus and placenta, there was a steady rise in the serum levels of albumin. At surgery no other cause of the ascites was ascertained by inspection and exploration of other intra-abdominal organs.

Due to the nature of the disease which affects all the systems in the body and in keeping with the recommendation by Calvin et $\mathrm{al}^{3}$ the renal, hematological and liver systems were all assessed for any abnormalities. The elevated levels of the transaminases and bilirubin is due to the effect of hypoxia on the liver in preeclamptic pregnancy which causes necrosis and degeneration of hepatocytes ${ }^{9}$. The total and direct bilirubin, platelet count and the electrolytes, urea and creatinine were all within normal limits.

With the delivery of the placenta which is the trigger for the development of preeclampsia, the endothelial cell dysfunction is gradually rectified, this coupled with the rising serum albumin, use of furosemide and spironolactone and control of the blood pressure, triggered the ascites to DOI: http://dx.doi.org/10.24018/ejmed.2019.1.5.106 resolve. No attempt at draining the peritoneal fluid in the post-operative period was made because of the risk of introducing infection. There was no manifest difficulty in breathing implying that the shift of fluid did not affect the pulmonary system. Transfusion of albumin to correct the hypoalbuminemia has been described and was effected in the management of ascites in this situation with favourable result ${ }^{7,8}$. However, Ascites has been reported to persist for up to 12 days post-delivery of the fetus and the placenta ${ }^{1}$.

The patient developed heart failure on the $3^{\text {rd }}$ day postdelivery, Calvin et $\mathrm{al}^{3}$ and Woods et $\mathrm{al}^{10}$ reported that ascites, especially in large volumes, would cause respiratory compromise and increased incidence of heart failure. The patient susceptible to developing heart failure does so in the first 24 hours post partum ${ }^{10}$. She was managed with blood transfusion, diuretics (frusemide and spironolactone) and controlled fluid administration. The antihypertensives were tailed off to avoid rebound hypertension and the patient was normotensive subsequently.

\section{CONCLUSION}

The actual etiology of ascitis in preeclampsia is still murky, nevertheless, with the little understanding of the pathophysiology, significant management success have been achieved and reported. Ascites is an unusual and uncommon complication of preeclampsia, a detail history, astute clinical examination and the use of ultrasonography is needed for prompt diagnosis so that appropriate multidisciplinary management can be instituted. The presence of fluid in the peritoneal cavity on ultrasound in a patient with preeclampsia is a telltale sign. Furthermore, following Caesarean section there will be some blood in the peritoneal cavity, this mixed with ascitic fluid in the face of abdominal distension may give the erroneous impression of continuous intraperitoneal bleeding. This may lead to unnecessary laparotomy with attendant increased morbidity and mortality. Therefore practitioners should have this in mind.

\section{ACKNOWLEDGMENT}

Authors appreciates Dr Anthony Eguvbe for his assistance and Miss Happiness Ndunuwe for typing this manuscript.

\section{REFERENCES}

[1] McCormick J, Criss P. Ultrasound Detection of Massive Maternal Abdominal Ascites in the Preeclamptic Patient. J of Diag Med Sonography. $\quad 1985 ; 1,268-271$. https://doi.org/10.1177/875647938500100606

[2] Calvin S, Silva M, Weinstein L, Finley $P$, Witte M. Characterization of ascites present at cesarean section. Am J Perinatol. 1991;8:99-102

[3] Vaijyanath AM, Nayar B, Malhotra N, Deka D. Massive ascites in severe pre-eclampsia: A rare complication. J Obstet Gynaecol Res 2002;28:199-202

[4] Ching Ding D, Hsu S, Su HY, Chu TW. Massive ascites in severe preeclampsia. Taiwanese J Obstet Gynecol. 2005;44:384-6

[5] Wirawan JP, Prasmusinto D. The unique presentation of massive ascites complicating severe preeclampsia and HELLP syndrome. Indones J Obstet Gynecol 2011;35-2:67-9. 
[6] Koseoglu SB, Deveer R, Camuzcuoglu A, Kasap B, Camuzcuoglu H. Massive Ascites and Pleural Effusion in Preeclampsia. J Clin Diagn Res. 2017;11(2):QD08-QD09. doi: $10.7860 / J C D R / 2017 / 22849.9416$

[7] Boldt J. Use of albumin: an update. Br. J. Anaesth. 2010;104:27684. doi: 10.1093/bja/aep393

[8] Brown MA, Zammit VC, Lowe SA. Capillary permeability and extracellular fluid volumes in pregnancy-induced hypertension. Clin Sci (Lond) 1989;77:599-604.

[9] Cines DB, Pollak ES, Buck CA, Loscalzo J, Zimmerman GA, McEver RP et al. Endothelial cells in physiology and in the pathophysiology of vascular disorders. Blood. 1998;91:3527-61.

[10] Woods JB, Blake PG, Perry KG, Magann EF, Martin RW, Martin JN. Ascites: a portent of cardiopulmonary complications in the preeclamptic patient with the syndrome of hemolysis, elevated liver enzymes, and low platelets. Obstet Gynecol. 1992; 80(1):8791

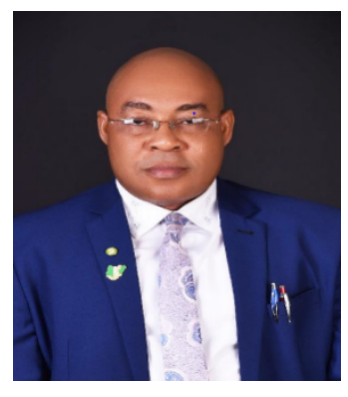

Dr. Alabrah Peter Waibode was born in Benin City in Edo State Nigeria. He had his initial primary education at Cavegina primary in Warri and later State School Agbere. His secondary and tertiary education were both at Port Harcourt in Nigeria. He qualified as a medical practitioner with MBBS from the University of Port Harcourt and is a fellow of the West African College of Surgeons majoring in Obstetrics and Gynecology after undergoing residency training at the University of Benin Teaching Hospital. He holds an executive master degree in public administration and is presently the Consultant-in-Charge Federal Medical Centre Yenagoa and an adjunct lecturer in the department of Obstetrics and gynecology at the Niger Delta University, in Bayelsa State Nigeria.

Corresponding author, email; alabrahpee@gmail.com

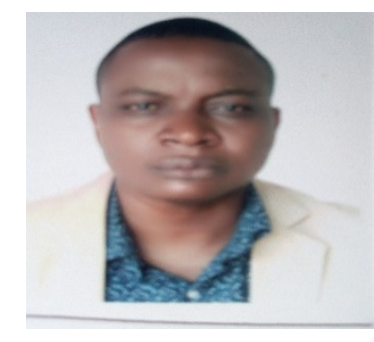

Email: agbodrjohn@yahoo.com

Dr John Agbo is a Consultant at the department of Obstetrics and Gynaecology, Federal Medical Center Yenagoa, Bayelsa State, Nigeria. He is a fellow of the West African College of Surgeons. He had his post graduate medical training at the Federal Medical Center Yenagoa and University of Port Harcourt teaching Hospital and under graduate medical education at the Ebonyi State University Abakaliki, Ebonyi state.

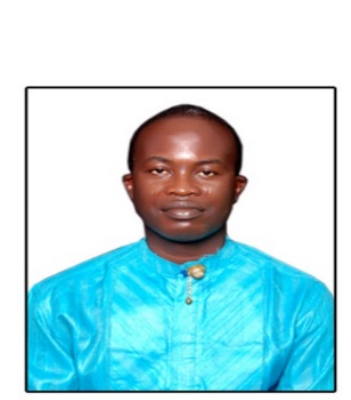

Dr. Eni-yimini Solomon Agoro holds a Bachelor's Degree in Medical Laboratory Science (Chemical Pathology) and Master's Degree in Chemical Pathology from the Rivers State University of Science and Technology, Nkpolu, RIvers State, Nigeria. He went further to bag another Master's Degree in Forensic Science specializing in Forensic Toxicology and Ph.D in Toxicology from the Nnnamdi Azikiwe University, Awka, Anambra State, Nigeria and the Abia State University, Uturu,

Email; enisagoro@gmail.co 